\title{
Unsteady Pressures Influenced by Trapped Air Pockets in Water-Filled Pipelines
}

\author{
Anton Bergant $1,{ }^{*}$ - Arris Tijsseling 2 - Young-il Kim³ ${ }^{3}$ - Uroš Karadžićc \\ Ling Zhou ${ }^{5}$ - Martin F. Lambert ${ }^{6}$ - Angus R. Simpson 6 \\ ${ }^{1}$ Litostroj Power d.o.o., Slovenia \\ 2 Technical University Eindhoven, The Netherlands \\ ${ }^{3}$ Detection Services, Australia \\ 4 University of Montenegro, Montenegro \\ ${ }^{5}$ Hohai University, China \\ 6 University of Adelaide, Australia
}

Trapped air pockets may cause severe operational problems in water-filled pipelines. This paper investigates the dynamic behaviour of a single trapped air pocket. A single air pocket creates distinct changes of amplitude, shape and timing of unsteady flow pressure waves when it is located at some point in a pipeline. The severity of the resulting hydraulic transients depends on the size, pressure and position of the trapped air pocket. In this paper, the air pocket is incorporated as a boundary condition in the discrete gas cavity model (DGCM) that also considers the effects of unsteady skin friction. Two distinct case studies are presented: (1) start-up test case (flow starting from rest) and (2) shut-down test case (flow stoppage). The start-up test case has been performed in the University of Montenegro pipeline apparatus (length $55 \mathrm{~m}$, internal diameter $18 \mathrm{~mm}$ ). A trapped air pocket is confined at the downstream end of the pipeline. The transient event is initiated by rapid opening of a valve positioned at the initial air/water interface. The shut-down test case has been carried out in the University of Adelaide laboratory apparatus (length $37 \mathrm{~m}$, internal diameter $22 \mathrm{~mm}$ ). A trapped gas pocket is maintained near the midpoint of the pipeline. The shut-down event is initiated by rapid closure of the downstream-end valve. Results of numerical simulations and laboratory investigations are presented and they show profound effects of unsteady skin friction on pressure histories.

Keywords: fluid transients, water hammer, trapped air pocket, discrete gas cavity model, unsteady skin friction, pipeline apparatus

Highlights

- $\quad$ Trapped air (gas) pockets cause changes in attenuation, shape and timing of pressure waves.

- Gas pocket is incorporated as boundary condition in discrete gas cavity model (DGCM).

- $\quad$ Start-up and shut-down experiments affected by one trapped gas pocket are investigated.

- Unsteady skin friction may significantly increase damping of pressure waves.

\section{O INTRODUCTION}

Liquid-conveying piping systems should work safely over a broad range of operating conditions. The control of air pockets may be a major problem in piping systems [1] and [2]. Air may be found in water pipelines mainly as stationary pockets or moving bubbles of various sizes. Air pockets can develop in a pipeline by bubble entrainment at inflow locations (such as at headrace tunnel intake structure, pump sump) and by gas release as the water pressure falls (steady or unsteady flow conditions) or the temperature rises. In addition, residual air may be trapped at an air valve if the air discharge through the valve is not properly controlled [3] and [4]. Transport of large pockets of air can also occur during filling and emptying of pipelines. Air movement along the pipeline can be slow during filling and the air column can become trapped adjacent to a closed valve or at a high point thus separating two water columns. Homogeneously distributed air bubbles or trapped air pockets in a liquid pipeline system can significantly reduce pressure wave propagation velocity (wave speed) and cause changes in the attenuation, shape and timing of pressure waves. This depends on the amount of the air in bubbles and pockets [5] and [6]. Air removal is traditionally performed using air valves. Correctly designed and sized air valves release unwanted air out of the pipeline in a controlled and safe manner. Dynamic effects of poorly selected air valves may cause large pressure peaks (air valve slam) as found by Campbell [7] and recently reviewed by Ramezani et al. [8].

The effects of entrapped air on hydraulic transients can be either beneficial or detrimental, with the outcome being entirely dependent on the layout of the piping system, the size and location of the air pocket(s), and the type of transient event (valve closure or opening, pump start-up or failure, turbine shut-down). The influence of air is more profound in low-pressure systems. Hydraulic transients in a pipeline that contains air pockets may 
create pressure spikes that are either greater than or less than those that would occur without any air as a result of reflections from the interfaces between the liquid and the air pockets [6] and [9]. The most severe pressure rise occurs during the rapid acceleration of a liquid column towards a volume of air that is completely confined [10] and [11]. The maximum pressure can be higher than the Joukowsky pressure if the transient is generated rapidly. However, a large air cavity may alternatively act as an air cushion that attenuates pressure surges in a pipeline. Numerical and experimental studies of dynamic behaviour resulting from entrapped air pockets in pipelines have been previously presented by Martin [10] in his pioneer work, and most recently by Zhou et al. [12] Numerical models are both based on rigid-column theory for systems with relatively large air pockets and on elastic water-hammer theory for systems with smaller air pockets [12]. The liquid column length may be assumed as constant (for a lumped gas pocket of relatively small volume) or as variable (air/water interface is allowed to move, long air columns).

This paper brings together and further explores unsteady pressures influenced by relatively small trapped air (gas) pockets in two nominally 'unsteadyfriction dominated' liquid-filled pipelines [13]: (1) University of Montenegro pipeline apparatus (length $55.37 \mathrm{~m}$, internal diameter $18 \mathrm{~mm}$ ) [14] and (2) University of Adelaide laboratory apparatus (length $37.32 \mathrm{~m}$, internal diameter $22.1 \mathrm{~mm}$ ) [15]. Trapped gas pockets are incorporated as (internal and end) boundary conditions (discrete gas cavities) in the discrete gas cavity model (DGCM) [5]. Isentropic behaviour is assumed for relatively large trapped gas pockets and an isothermal bath for small gas cavities. In addition, a computationally efficient and accurate convolution-based unsteady skin friction term [16] is incorporated in the DGCM. This is essential because numerical and experimental investigations herein show that the fully-developed pressure traces may be strongly attenuated by unsteady friction. Unsteady friction has not been used by other authors for analysis of the effects of trapped gas pockets in waterfilled pipelines. Treatment of very large trapped gas volumes (long gas columns) is beyond the scope of this paper. Details on modelling of very long trapped gas columns can be found in the literature including Chaiko and Brinckman [17], Malekpour and Karney [18], and most recently by Tijsseling et al. [19]. The DGCM developed in this paper is then validated against the results from two distinct experimental runs: (1) start-up test case (flow starting from rest such as for a pump start-up or a valve opening) [14] and (2) shut-down test case (flow stoppage - such as for a pump failure or a valve closure) [15]. The startup test case has been performed in the University of Montenegro pipeline apparatus. A trapped gas pocket is captured between two ball valves at the downstream-end of the pipeline. The transient event is triggered by rapid opening of the valve that initially separates the water column and air pocket; the downstream-end valve stays closed during the event. The shut-down test case has been carried out in the University of Adelaide laboratory apparatus. In this apparatus the trapped gas pocket is captured at the midpoint of the pipeline in a specially designed airpocket device. The shut-down event is initiated by the rapid closure of a side-discharge solenoid valve positioned at the downstream-end of the pipeline.

\section{THEORETICAL MODELLING}

A DGCM with consideration of unsteady skin friction effects is presented in this Section. Unsteady pipe flow is described by the continuity equation and the equation of motion [3] and [5]. The method of characteristics (MOC) transformation of the unsteady pipe flow equations gives the water hammer solution procedure. The DGCM allows gas cavities to grow at computational sections in the MOC numerical grid [5]. Trapped gas pockets are incorporated as (internal and end) boundary conditions (discrete gas cavities).

\subsection{Unsteady Pipe Flow Equations}

Water-hammer refers to the transmission and reflection of pressure waves in liquid-filled pipelines. Unsteady pipe flow is described by the continuity equation and the equation of motion [5]

$$
\begin{gathered}
\frac{\partial H}{\partial t}+V \frac{\partial H}{\partial x}-V \sin \theta+\frac{a^{2}}{g} \frac{\partial V}{\partial x}=0, \\
g \frac{\partial H}{\partial x}+\frac{\partial V}{\partial t}+V \frac{\partial V}{\partial x}+f \frac{V|V|}{2 D}=0 .
\end{gathered}
$$

All symbols are defined in Section 6. The flow in the pipe is assumed to be uni-directional (with crosssectional averaged velocity and pressure distributions), the pressure always remains greater than the liquid vapour pressure, the pipe wall and liquid behave linearly elastically, unsteady friction losses are usually approximated as steady friction losses, the amount of free gas in the liquid is negligible, fluid-structure coupling is negligible, and there are no leakages and blockages along the pipe. For most acoustic problems, the transport terms $V(\partial H / \partial x), V(\partial V / \partial x)$ and $V \sin \theta$, are 
very small compared to the other terms and may be neglected [5] and [20]. A simplified form of Eqs. (1) and (2) using the discharge $Q=V A$ instead of the flow velocity $V$ leads to

$$
\begin{gathered}
\frac{\partial H}{\partial t}+\frac{a^{2}}{g A} \frac{\partial Q}{\partial x}=0, \\
\frac{\partial H}{\partial x}+\frac{1}{g A} \frac{\partial Q}{\partial t}+f \frac{Q|Q|}{2 g D A^{2}}=0 .
\end{gathered}
$$

The method of characteristics transformation of the simplified Eqs. (3) and (4) produces the waterhammer compatibility equations which are valid along the characteristics lines [5] and [20]. The compatibility equations in finite-difference form are numerically stable unless the friction is dominant and the computational grid is coarse and, when written for computational section $i$, are [5]:

- along the $\mathrm{C}^{+}$characteristic line $(\Delta x / \Delta t=a)$

$$
\begin{aligned}
& H_{i, t}-H_{i-1, t-\Delta t}+\frac{a}{g A}\left(\left(Q_{u}\right)_{i, t}-\left(Q_{d}\right)_{i-1, t-\Delta t}\right)+ \\
& \frac{f \Delta x}{2 g D A^{2}}\left(Q_{u}\right)_{i, t}\left(Q_{d}\right)_{i-1, t-\Delta t} \mid=0,
\end{aligned}
$$

- along the $\mathrm{C}^{-}$characteristic line $(\Delta x / \Delta t=-a)$

$$
\begin{aligned}
& H_{i, t}-H_{i+1, t-\Delta t}-\frac{a}{g A}\left(\left(Q_{d}\right)_{i, t}-\left(Q_{u}\right)_{i+1, t-\Delta t}\right)- \\
& \frac{f \Delta x}{2 g D A^{2}}\left(Q_{d}\right)_{i, t}\left|\left(Q_{u}\right)_{i+1, t-\Delta t}\right|=0 .
\end{aligned}
$$

The discharge at the upstream side of the computational section $\left(\left(Q_{u}\right)_{i}\right)$ and the discharge at the downstream side of the section $\left(\left(Q_{d}\right)_{i}\right)$ are identical for the pure water-hammer case where pressures remain above vapour pressure (transient liquid flow). At a boundary (reservoir, valve, pump, turbine), a devicespecific equation replaces one of the water-hammer compatibility equations.

\subsection{Discrete Gas Cavity Model (DGCM)}

The DGCM allows gas cavities to develop at computational sections in the MOC numerical grid. A liquid phase with a constant wave speed $a$ is assumed to occupy each computational reach. The DGCM is described by the two water-hammer compatibility Eqs. (5) and (6), the continuity equation for the gas cavity volume, and the ideal gas equation [5]. Numerical forms of the continuity equation for the gas cavity volume and the ideal gas equation within the staggered grid of the method of characteristics are:
- continuity equation for the gas volume

$$
\begin{aligned}
& \left(\forall_{g}\right)_{i, t}=\left(\forall_{g}\right)_{i, t-2 \Delta t}+\psi\left(\left(Q_{d}\right)_{i, t}-\left(Q_{u}\right)_{i, t}\right) 2 \Delta t+ \\
& (1-\psi)\left(\left(Q_{d}\right)_{i, t-2 \Delta t}-\left(Q_{u}\right)_{i, t-2 \Delta t}\right) 2 \Delta t,
\end{aligned}
$$

- ideal gas equation for the gas pocket

$$
\left(H_{i, t}-z_{i}-h_{v}\right)\left(\forall_{g}\right)_{i, t}^{n}=\left(H_{0}-z_{0}-h_{v}\right)\left(\forall_{g 0}\right)^{n} \text {. }
$$

The polytropic exponent $n$ has values between 1 (isothermal, traditionally used for small gas cavities) and 1.4 (isentropic, used in our simulations for the relatively large trapped gas pocket). The nonlinear system of equations is solved numerically.

The DGCM has been successfully used both for the simulation of gaseous and vaporous cavitation (vaporous cavitation: gas void fraction $\alpha_{g 0} \leq 10^{-7}$; $\alpha_{g 0}=\forall_{g 0} / \forall_{\text {reach }} ; \quad \forall_{\text {reach }}=A_{i} \Delta x$ ). In the latter case, when the discrete cavity volume calculated by Eq. (7) is negative (cavity collapse), then the cavity volume is recalculated by Eq. (8) (by definition: small cavity exists at each computational section at all times).

\subsection{Unsteady Skin Friction}

Traditionally the steady skin friction term is incorporated in the water-hammer algorithm. This is satisfactory for slow transients where the wall shear stress has a quasi-steady behaviour. Previous investigations using the steady friction approximation for rapid transients [21] to [23] showed significant discrepancies in attenuation, shape and timing of pressure traces when computational results were compared with results of measurements. The skin friction factor, explicitly used in Eqs. (5) and (6), can be expressed as the sum of a steady part $f_{s}$ and an unsteady part $f_{u}$ as proposed by Vardy [24] and his coworkers [25], and Meniconi et al. [26]

$$
f=f_{s}+f_{u} .
$$

The steady friction factor $f_{s}$ depends on Reynolds number and relative pipe roughness. When the steady friction factor is updated at each time step during simulation, it is referred as quasi-steady friction factor (QF). A number of unsteady friction models has been proposed in the literature including one-dimensional (1D) and two-dimensional (2D) models [21] to [23], and recently three-dimensional (3D) model [27]. The 1D models take into account the actual 2D crosssectional velocity profile and corresponding viscous losses in different ways. The 2D models compute the actual cross-sectional velocity profile continuously during the water-hammer event. The recent 3D model 
better captures local and convective accelerations and serves as a 'numerical laboratory' for testing 1D and 2D models. This paper deals with the convolutionbased unsteady friction model developed by Zielke [28]. Zielke analytically developed the convolutionbased model of unsteady friction (UF) for transient laminar flow. The unsteady part of the friction factor in Eq. (9) is defined by the convolution of a weighting function with past temporal flow-rate accelerations

$$
f_{u}=\frac{32 v A}{D Q|Q|} \int_{0}^{t} \frac{\partial Q}{\partial t^{*}} W_{0}\left(t-t^{*}\right) d t^{*}
$$

Zielke evaluated Eq. (10) using the full convolution scheme, which is computationally intensive (long time simulations). Vítkovský et al. [16] developed an efficient and accurate method that makes an approximation of the weighting function $W(\tau)$ by a finite sum of $N_{W}$ exponential terms:

$$
W_{\text {app }}(\tau)=\sum_{k=1}^{N_{W}} m_{k} e^{-n_{k} \tau} .
$$

The unsteady part of the friction factor is defined as:

$$
f_{u}=\frac{32 v A}{D Q|Q|} \sum_{k=1}^{N_{W}} y_{k}(t)
$$

in which the component $y_{k}(t)$ is expressed as

$$
y_{k}(t)=\int_{0}^{t} \frac{\partial Q}{\partial t^{*}} m_{k} e^{-n_{k} K\left(t-t^{*}\right)} d t^{*} .
$$

The constant factor $K\left(=4 v / D^{2}\right)$ converts the time $t$ into the dimensionless time $\tau=4 v t / D^{2}$. At time $t+2 \Delta t$ the component $y_{k}$ is

$$
y_{k}(t+2 \Delta t)=\int_{0}^{t+2 \Delta t} \frac{\partial Q}{\partial t^{*}} m_{k} e^{-n_{k} K\left(t+2 \Delta t-t^{*}\right)} d t^{*} .
$$

Integration of Eq. (14) in terms of the dimensionless time step $\Delta \tau(=K \Delta t)$ gives an efficient recursive expression for the component $y_{k}$ and hence for $f_{u}$

$$
\begin{aligned}
y_{k}(t+2 \Delta t)= & e^{-2 n_{k} K \Delta t} y_{k}(t)+ \\
& m_{k} e^{-n_{k} K \Delta t}[Q(t+2 \Delta t)-Q(t)] .
\end{aligned}
$$

The convolution is still there, but it is dealt with efficiently through exponential functions. The coefficients of the exponential sum $\left(m_{k}\right.$ and $\left.n_{k}\right)$ have been developed both for Zielke's weighting function for transient laminar flow [28] and for Vardy-Brown's weighting functions for transient turbulent flow [29] and [30] and can be found in Vítkovský et al. [16]. The Vítkovský et al. [16] model is accurate over a wide range of dimensionless times $\Delta \tau\left[10^{-6}, 10^{-1}\right]$ and this condition has been considered in all simulations presented in Sections 3.1 and 3.2. It should be noted that for lower $\Delta \tau$ values Urbanowicz [31] and [32] developed a computationally efficient and accurate approximation of weighting functions that can be used when $\Delta \tau \leq 10^{-6}$. In addition, the UF cannot produce the small low frequency shift observed in experimental results. The measured wave speed is slightly lower than the classical theoretical one as the liquid has extra inertia due to the unsteady velocity profile, which is asymptotically related to the momentum correction factor as found by Schönfeld [33]. The momentum correction factor is relatively constant during the transient event and can be found in Chen [34]. Its value is close to 1 .

\section{LABORATORY TEST FACILITIES}

Experiments with trapped air pockets have been performed in two laboratory test facilities. Tests with flow starting from rest have been carried out in the University of Montenegro pipeline apparatus [14] and tests with flow stoppage in the University of Adelaide apparatus [15].

\subsection{Montenegro Pipeline Apparatus}

A multi-purpose pipeline apparatus has been designed and constructed at the Faculty of Mechanical Engineering, University of Montenegro, for investigating rapid water-hammer events including column separation and fluid-structure interaction. The apparatus is comprised of a horizontal steel pipeline (total length of $55.37 \mathrm{~m}\left(U_{x}= \pm 0.01 \mathrm{~m}\right)$; internal diameter of $18 \mathrm{~mm}\left(U_{x}= \pm 0.1 \mathrm{~mm}\right)$; pipe wall thickness of $\left.2 \mathrm{~mm}\left(U_{x}= \pm 0.05 \mathrm{~mm}\right)\right)$ that connects the upstream-end high-pressurized tank (Tank 1) to the outflow tank (Tank 2) - see Fig. 1. The uncertainty in a measurement $U_{x}$ is expressed as the root-sum-square combination of bias and precision error [35]. Four valve units are positioned along the pipeline including the end points. The valve units at the upstream-end tank (position 0/3) and at the two equidistant positions along the pipeline (positions $1 / 3$ and 2/3) consist of two hand-operated ball valves that are connected to the intermediate pressure transducer block. A T-section with an on/off air inlet valve is installed between the upstream end valve unit (position 0/3) and the high-pressurized tank to facilitate pipeline emptying tests. The horizontal pipe upstream-end service valve is installed between the T-section and the high-pressurized tank in order to isolate upstream-end 
tank during emptying tests. There are four $90^{\circ}$ bends along the pipeline with radius of curvature $R_{b}=3 D$. The pipeline is anchored against axial movement at 37 points (as close as possible to the valve units and bends). The air in the upstream-end tank can be adjusted up to $800 \mathrm{kPa}$ gauge pressure. Pressure in the tank is kept constant during each experimental run by using a high precision fast-acting air pressure regulator (precision class: $0.2 \%$ ) in the compressed air supply line.

Four dynamic high-frequency pressure transducers are positioned within the valve units along the pipeline including the end points (see Fig. 1). Pressures $p_{0 / 3}, p_{1 / 3}, p_{2 / 3}$ and $p_{3 / 3}$ are measured by Dytran 2300V4 high-frequency flush-mounted piezoelectric pressure transducers (absolute pressure range: up to $0 \mathrm{MPa}$ to $6.9 \mathrm{MPa}$; resonance frequency: $500 \mathrm{kHz}$; acceleration compensated; discharge time constant: 10 seconds (fixed); $U_{x}= \pm 0.1 \%$ ). An Endress+Hauser PMP131 strain-gauge pressure transducer has been installed at the control valve $\mathrm{V} 3 / 3 \mathrm{C}$ (pressure $p_{3 / 3-s g}$; pressure range: $0 \mathrm{MPa}$ to 1 $\mathrm{MPa} ; U_{x}= \pm 0.5 \%$ ) to measure (1) initial pressure in the confined space between the valves $V 3 / 3 \mathrm{E}$ and $\mathrm{V} 3 / 3 \mathrm{H}$ (or $\mathrm{V} 3 / 3 \mathrm{P}$ ), and (2) transient response of a trapped air pocket after rapid opening of either $\mathrm{V} 3 / 3 \mathrm{H}$ or V3/3P. The water temperature is monitored by a thermometer installed in the outflow tank. The waterhammer wave speed was determined as $a=1340 \mathrm{~m} / \mathrm{s}$ $\left(U_{x}= \pm 0.1 \%\right)$.

The experimental start-up run with a confined trapped air pocket at the downstream-end valve (V3/3E - see Fig. 1) is carried out as follows. The pressure in the upstream-end Tank 1 is adjusted to a desired value using the high precision air pressure regulator. The control needle valve $(\mathrm{V} 3 / 3 \mathrm{C})$ is fully open. The upstream-end valve $(\mathrm{V} 0 / 3 \mathrm{U})$ at the pressurized tank (position 0/3 in Fig. 1) is closed. All other valves of the four valve units are fully open. The air inlet valve (V0/3A) is closed (isolation of the compressed air supply into the pipeline), and the downstream-end emptying valve (V3/3E) is open. The filling of the initially empty pipeline is initiated by opening the valve $\mathrm{V} 0 / 3 \mathrm{U}$. When steady state flow conditions are reached, the downstream-end valve (either $\mathrm{V} 3 / 3 \mathrm{P}$ or $\mathrm{V} 3 / 3 \mathrm{H}$ ) is closed as fast as possible.

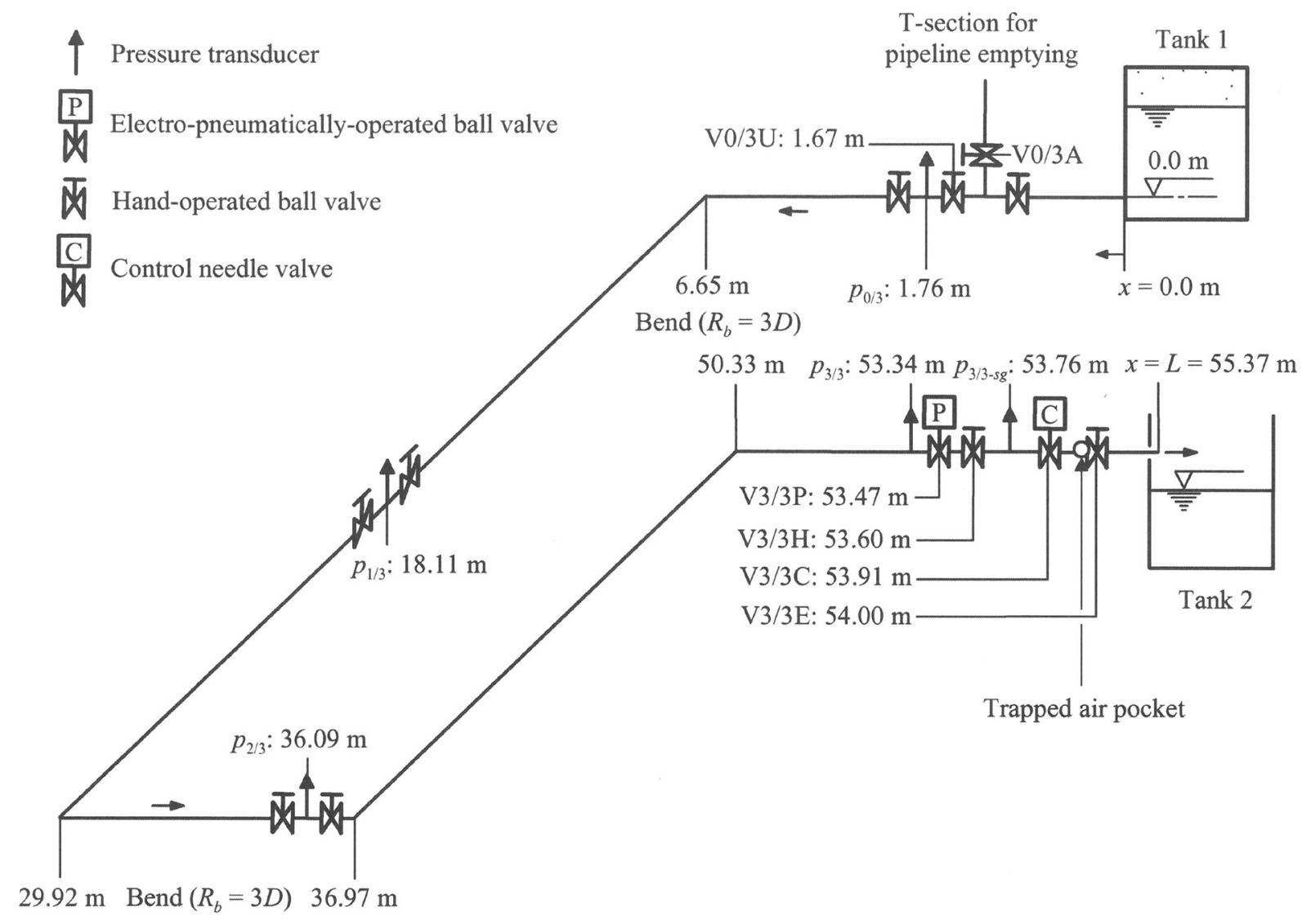

Fig. 1. Montenegro pipeline apparatus (total length $L=55.37 \mathrm{~m}$; diameter $D=18 \mathrm{~mm}$ ) 
After complete valve closure, a large amount of water is flushed downstream the valve into the outflow tank. The pressure downstream of the closing valve drops to the atmospheric pressure and upstream the valve the reservoir pressure remains. Then the emptying valve $\mathrm{V} 3 / 3 \mathrm{E}$ is closed. The system is now ready for experiments. The start-up experiment is initiated by the rapid opening of the hand-operated valve $\mathrm{V} 3 / 3 \mathrm{H}$ (or V3/3P). It should be noted that the space between the valves $\mathrm{V} 3 / 3 \mathrm{E}$ and $\mathrm{V} 3 / 3 \mathrm{H}$ (or $\mathrm{V} 3 / 3 \mathrm{P}$ ) is occupied by air and residual water due to the inline control valve V3/3C which prevents full flushing. This deficiency will be removed in the near future by adequate redesign of the pipeline outlet. Therefore, the initial value of the trapped gas volume is estimated by a trial and error method based on best fit between the measured and computed first pressure peak at the valve.

\subsection{Adelaide Pipeline Apparatus}

A versatile pipeline apparatus for investigating water hammer and column separation in pipelines was constructed in the Robin Hydraulics Laboratory at the University of Adelaide, Australia. The apparatus has been modified to investigate the effects of inline boundaries on transients [36] including the effect of a trapped gas pocket. The modified apparatus comprises a straight $37.32 \mathrm{~m}(37.53 \mathrm{~m}$ including a service valve; $U_{x}= \pm 0.01 \mathrm{~m}$ ) long sloping copper pipe of $22.1 \mathrm{~mm}\left(U_{x}= \pm 0.1 \mathrm{~mm}\right)$ internal diameter and of $1.63 \mathrm{~mm}\left(U_{x}= \pm 0.05 \mathrm{~mm}\right)$ wall thickness connecting two pressurized tanks (Tanks 1 and 2 in Fig. 2). The upward pipe slope is constant at $5.45 \%\left(U_{x}= \pm 0.01\right.$
\%). A specified pressure in each of the tanks is controlled by a computerized pressure control system. The net water volume in both tanks and the capacity of the air compressor limits the maximum steady state velocity to $1.5 \mathrm{~m} / \mathrm{s}$; the maximum operating pressure in each tank is $690 \mathrm{kPa}$. The pressure waves are recorded by four high-resolution flush-mounted strain-gauge pressure transducers Druck PDCR 810 (absolute pressure range: $0 \mathrm{MPa}$ to $6 \mathrm{MPa}$; resonance frequency: $>360 \mathrm{kHz} ; U_{x}= \pm 0.3 \%$ ). The two transducers are located at the end tanks: $p_{0 / 2}$ and $p_{2 / 2}$, and the two at the midpoint: $p_{1 / 2 \mathrm{U}}$ and $p_{1 / 2 \mathrm{D}}$ (one below the pipe axis at the trapped air pocket device and one $1.34 \mathrm{~m}$ downstream of the device, respectively) - see Fig. 2.

A special trapped air pocket device is installed practically at the midpoint of the pipeline (Fig. 2). Four screw bolt type devices with trapped air volumes of $\forall_{g 0,1 / 2 \mathrm{U}}=\{0.43 ; 1.20 ; 3.93 ; 48.0\} \times 10^{-7} \mathrm{~m}^{3}$ have been designed and constructed. The device has a hole drilled in the middle and it is inserted in a brass block. The cavity volume of the air pocket devices can be measured by using the diameter and depth of holes or by using $1.25 \mathrm{~cm}^{3}$ micro centrifuge tube with a conical bottom. The experimental procedure requires the careful removal of any residual air from the pipeline before the tests. The only air in the pipeline system should be trapped in the device.

Shut-down events are generated at the downstream location (at the left hand end in Fig. 2) by a side-discharge solenoid valve V2/2S with a very fast closing time (effective valve closure time of 4 $\mathrm{ms})$. The service valve at Tank $2 \mathrm{~V} 2 / 2 \mathrm{H}$ is closed at all times during transient runs. The initial flow velocity

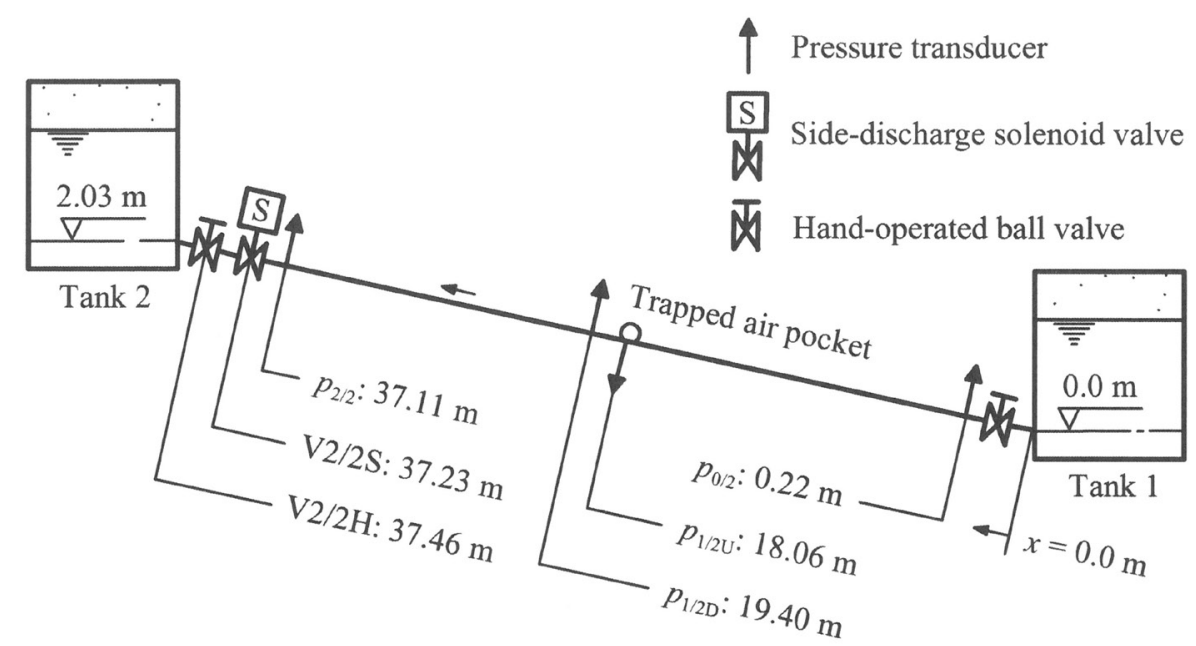

Fig. 2. Adelaide pipeline apparatus (total length $L=37.53 \mathrm{~m}$; internal diameter $D=22.1 \mathrm{~mm}$ ) 
( $U_{x}= \pm 1 \%$ for the volumetric method) is established by changing the pressure in the upstream end Tank 1. The water temperature is recorded by a thermometer installed in Tank 2 . The wave propagation velocity was determined as $a=1330 \mathrm{~m} / \mathrm{s}\left(U_{x}= \pm 0.1 \%\right)$.

\section{NUMERICAL AND EXPERIMENTAL RESULTS}

Laboratory measurements of hydraulic transient events in pipelines are traditionally used for validation of water-hammer software packages. The case studies herein present two typical examples of validation of a trapped gas pocket boundary condition that is incorporated in the classical discrete gas cavity model [5] with unsteady skin friction term extension. Numerical results from the DGCM with consideration of QF and UF are compared with the results of laboratory measurements taken in Montenegro (Fig. 1) and Adelaide (Fig. 2) pipeline test facilities.

\subsection{Start-up Test Case (Montenegro Pipeline Apparatus): Air Pocket at Pipe End}

The flow start-up experiment is initiated by the rapid opening of the hand-operated downstream-end valve $\mathrm{V} 3 / 3 \mathrm{H}$ in the Montenegro test apparatus as explained in Section 2.1. Initially the air pocket is confined in the space between the valves V3/3E and V3/3H (Fig. 1) at atmospheric pressure and the liquid (water) in the pipeline is at static conditions (standstill water with Tank 1 pressure). The computed and measured results are presented for the case with initial static head in the upstream-end pressurized tank $H_{\mathrm{T} 1}=52 \mathrm{~m}$ (measured at datum level at the top of the pipe inlet at Tank 1 - Fig. $1)$ and an estimated initial trapped air pocket volume at atmospheric conditions $\forall_{g 0,3 / 3}=13 \mathrm{~cm}^{3}\left(1.3 \times 10^{-5}\right.$ $\mathrm{m}^{3} ; U_{x}= \pm 10 \%$ ). This air volume is very small in comparison to the total water volume in the pipeline of 13.6 litres $\left(13,600 \mathrm{~cm}^{3}\right)$. The minor losses (entrance, in-line ball valves and large-radius bends) have been neglected in numerical simulations. The magnitude of minor losses is less than $1 \%$ of the total line losses at different steady flow velocities of interest. Internal water and surrounding temperatures were about $25^{\circ} \mathrm{C}$ and $30^{\circ} \mathrm{C}$, respectively. Fig. 3 shows measured absolute heads $H^{*}$ air (pressure $p_{3 / 3-s g}$ ) in the area of the confined air pocket and $H_{3 / 3}^{*}$ (pressure $p_{3 / 3}$ ) at the upstream end of the electro-pneumatically-operated ball valve V3/3P $\left(H^{*}=\right.$ absolute head herein; $\left.H^{*}=H-z+H_{b}\right)$. The effective valve opening time of $t_{\text {oef }}=0.015 \mathrm{~s}$ is significantly shorter than the water-hammer wavereturn time of $2 L / a=0.080 \mathrm{~s}$. The effective valve opening time is also shorter than the time $t=0.15 \mathrm{~s}$ of occurrence of the maximum bulk head at the air pocket interface. The assumption of instantaneous valve opening used in the DGCM simulations is justified [12]. The maximum peak head occurs as short duration pressure pulse at time $t=0.175 \mathrm{~s}$. This peak pressure is due to the superposition of the trapped air pocket induced bulk head wave with the reservoir-reflected low pressure wave (two end-boundary-induced waves). The frequency of damped bulk pressure oscillations of 5 $\mathrm{Hz}$ is naturally lower than the first hydraulic frequency of the reservoir-pipeline-closed valve system of $6.2 \mathrm{~Hz}$ ( $\left.f_{h}=a /(4 L)[37]: a=1340 \mathrm{~m} / \mathrm{s}, L=54 \mathrm{~m}\right)$.

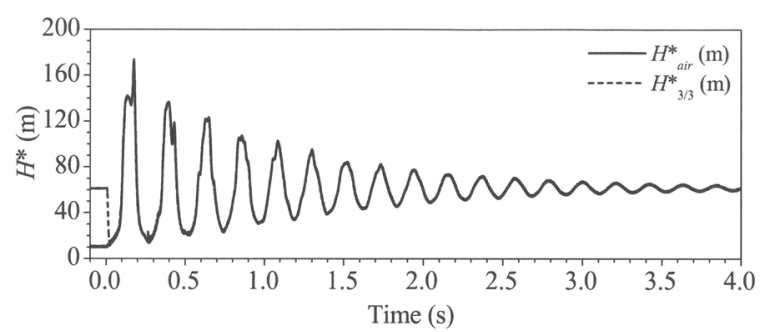

Fig. 3. Variation of measured absolute air and liquid heads at the downstream dead end $\left(H^{*}\right.$ air and $\left.H^{*}{ }_{3 / 3}\right)$ in Montenegro apparatus:

$$
H_{T 1}=52 \mathrm{~m} ; \forall_{\mathrm{g} 0,3 / 3}=13 \mathrm{~cm}^{3}
$$

Numerical results from the DGCM (as described in Section 1.2) are compared with results of the laboratory measurements at the downstream end valve (pressure $p_{3 / 3}$ in Fig. 1) and along the pipeline (pressures $p_{2 / 3}$ and $p_{1 / 3}$ in Fig. 1). The effect of unsteady friction is included in the simulations by using the Zielke weighting function for transient laminar flow [28]. The number of pipe reaches for all computational runs is $N=12$ and the time step is $\Delta t=0.0033 \mathrm{~s}$. The corresponding dimensionless time $\Delta \tau=4 v \Delta t / D^{2}=3.7 \times 10^{-5}$ in the Vítkovský et al. [16] unsteady friction weighting function approximation is well within the applicable range of the model (see Section 1.3). The DGCM void fraction at the downstream-end closed valve (location of the trapped air pocket) is of the order of $\alpha_{\mathrm{g} 0,3 / 3}=10^{-3}$ (at atmospheric conditions) and much larger than the void fractions of $\alpha_{\mathrm{g} 0}=10^{-7}$ at the other 11 computational sections (except $0.5 \times 10^{-7}$ at the upstream-end reservoir). Simulations using the isentropic relation for the trapped gas pocket and the isothermal one for the negligibly small gas cavities produce the best fit with the measured results for the considered case study. In addition, simulations with larger numbers of pipe reaches $\left(24,48 ; \alpha_{g 0,3 / 3}\right.$ is updated accordingly) produce practically the same results (showing the robustness of the DGCM). A weighting factor of $\psi=1$ has been used in the DGCM Eq. (7) [38]. 

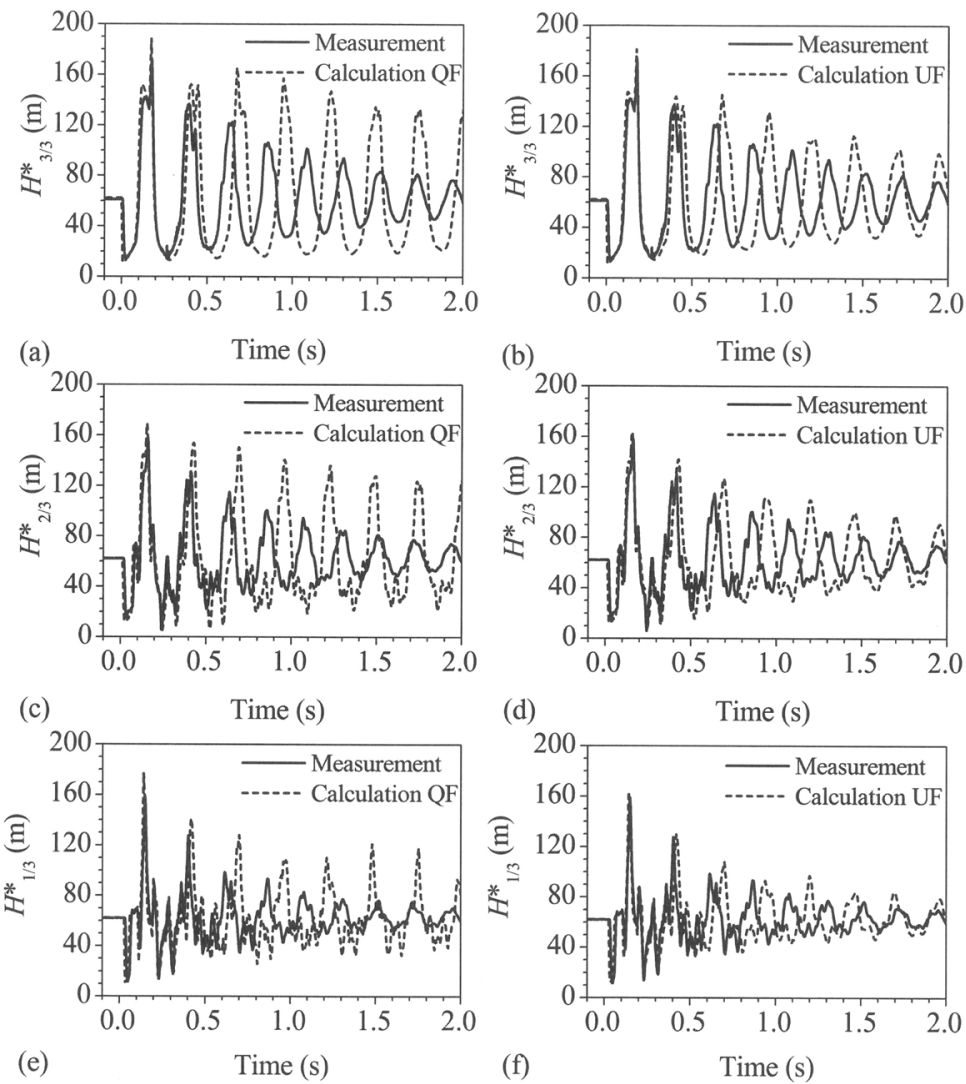

Fig. 4. Comparison of absolute heads at the downstream end $\left(H^{*}{ }_{3 / 3}\right)$ and along the pipeline $\left(H^{\star}{ }_{2 / 3}\right.$ and $\left.H^{\star}{ }_{1 / 3}\right)$ in Montenegro apparatus: $H_{T 1}=52 \mathrm{~m} ; \forall_{\mathrm{g} 0,3 / 3}=13 \mathrm{~cm}^{3}$

The results from the DGCM using the $\mathrm{QF}$ are presented in Figs. 4a $\left(H^{*}{ }_{3 / 3}\right), 4 \mathrm{c}\left(H^{*}{ }_{2 / 3}\right)$ and $4 \mathrm{e}\left(H^{*}{ }_{1 / 3}\right)$. There is a good match between maximum head peaks and pressure wave timing in the early phase of the transient event. However, the results significantly differ from the measurements both in attenuation and timing of pressure traces at later times. It is evident that the DGCM-QF (quasi-steady) model does not produce sufficient damping both for the bulk pressure traces and the short-duration pressure peaks. On the contrary, when using DGCM with UF model the results improve significantly not only in attenuation but also in timing - Figs. 4b $\left(H_{3 / 3}^{*}\right), 4 \mathrm{~d}\left(H_{2 / 3}^{*}\right)$ and $4 \mathrm{f}\left(H^{*}{ }_{1 / 3}\right)$ but there are still some discrepancies in timing and attenuation at later times. These discrepancies may be attributed to additional head losses at the control needle valve (not accounted for in the simulations) and possible air pocket separation and consequent entrainment of some air bubbles with reverse flow into the initial pure-liquid zone. Careful investigation of computed head traces in computational sections along the pipeline between the transducer positions $2 / 3$ and $3 / 3$ indicates a distributed vaporous cavitation zone that is condensed back to the liquid phase by the reservoir-reflected wave. Cavitation growth and collapse occurs within the time period $t$ is between 0.242 and 0.248 seconds. The propagation of the low pressure wave towards the trapped air pocket boundary and the reflected wave during this period can be visualized from heads at positions $1 / 3$ and $2 / 3$ (absolute heads $H^{*}{ }_{1 / 3}$ and $H^{*}{ }_{2 / 3}$ in Fig. 4). This unique case study exhibits both trapped air pocket and distributed vaporous cavitation at the same time.

\subsection{Shut-down Test Case (Adelaide Pipeline Apparatus): Air Pocket at Pipe Middle}

Shut-down is generated by rapid closure of the downstream-end side-discharge solenoid valve V2/2S in the Adelaide test apparatus as presented in Section 2.2. Fig. 5 (absolute head at the downstream end $\left(H^{*} / 2\right)$ ) and Fig. 6 (absolute head at the midpoint $\left.\left(H^{*}{ }_{1 / 2 \mathrm{D}}\right)\right)$ show computational and measured results for the case with initial flow velocity $V_{0}=0.137 \mathrm{~m} / \mathrm{s}$ at a constant static head in the upstream-end pressurized tank of $H_{\mathrm{T} 1}=51 \mathrm{~m}$ (measured at datum level at the 
top of the pipe inlet at Tank 1 - Fig. 2) and a trapped air pocket at atmospheric conditions of volume $\forall_{g 0,1 / 2 \mathrm{U}}=0.39 \mathrm{~cm}^{3}\left(3.93 \times 10^{-7} \mathrm{~m}^{3} ; U_{x}= \pm 5 \%\right)$ - see position of air pocket device in Fig. 2. The air volume is very small in comparison to the total water volume of $14,400 \mathrm{~cm}^{3}$ and therefore isothermal air behaviour is assumed in all simulations. Water and surrounding temperatures were $21^{\circ} \mathrm{C}$ and $22{ }^{\circ} \mathrm{C}$, respectively. The initial Reynolds number is $\operatorname{Re}_{0}=3,050\left(\operatorname{Re}_{0}=V_{0} D / v\right)$ and the respective approximated Vardy-Brown weighting function $W_{a p p}$ is taken from Vítkovský et al. [16]. The measured wave speed is $a=1330 \mathrm{~m} / \mathrm{s}$ and the estimated initial steady-state friction coefficient is $f_{0}=0.044$. Minor losses (entrance, ball valve) are small and neglected in the analysis (much less than $1 \%$ of total losses). The effective valve closure time of $t_{c e f}=0.004 \mathrm{~s}$ is significantly shorter than the waterhammer wave-return time of $2 L / a=0.056 \mathrm{~s}$.

The number of pipe reaches in the computational runs using the MOC-based DGCM is $N=54$
(55 computational sections) and the time step is $\Delta t=(L / N) / a=0.000519$ s. The dimensionless time $\Delta \tau=4 v \Delta t / D^{2}=4.2 \times 10^{-6}$ is within the applicable range of the Vítkovský et al. [16] model (see Section 1.3). A larger number of reaches (in comparison to the startup case) has been selected for accurate monitoring of pressure waves due to interaction with the trapped gas pocket. The trapped air pocket is at computational section 27 with $\alpha_{g 0,1 / 2 \mathrm{U}}=1.48 \times 10^{-3}$ (at atmospheric conditions) and the other 54 void fractions are taken $\alpha_{g 0}=10^{-7}$ (except $0.5 \times 10^{-7}$ at the end boundaries (reservoir and valve)). As in the start-up case, the $\psi=1$ has been used in Eq. (7).

Fig. 5 presents absolute head at the rapidly closed valve $\mathrm{V} 2 / 2 \mathrm{~S}$. After closure the pressure wave travels towards the trapped air pocket at the midpoint of the pipeline (position $1 / 2 \mathrm{U}$ in Fig. 2). The interaction of the pressure wave and the compressed air pocket is first recorded as spiky pressure drop (Fig. 6) at the pressure transducer closest to the trapped pocket
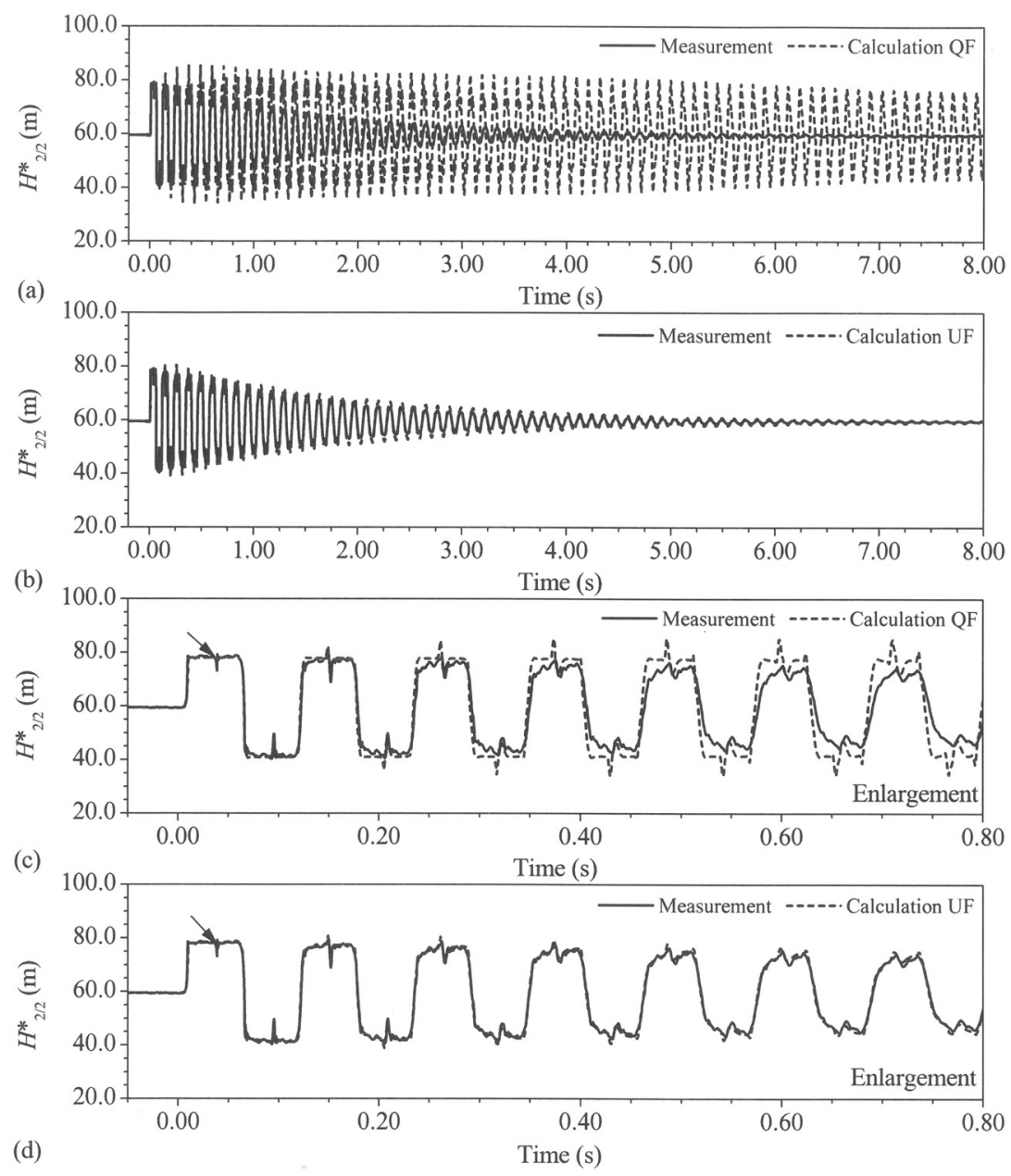

Fig. 5. Comparison of absolute heads at the downstream end $\left(H_{2 / 2}^{*}\right)$ in Adelaide apparatus: $H_{T 1}=51 \mathrm{~m} ; \forall_{\mathrm{g} 0,1 / 2 U}=0.39 \mathrm{~cm}^{3}$ 

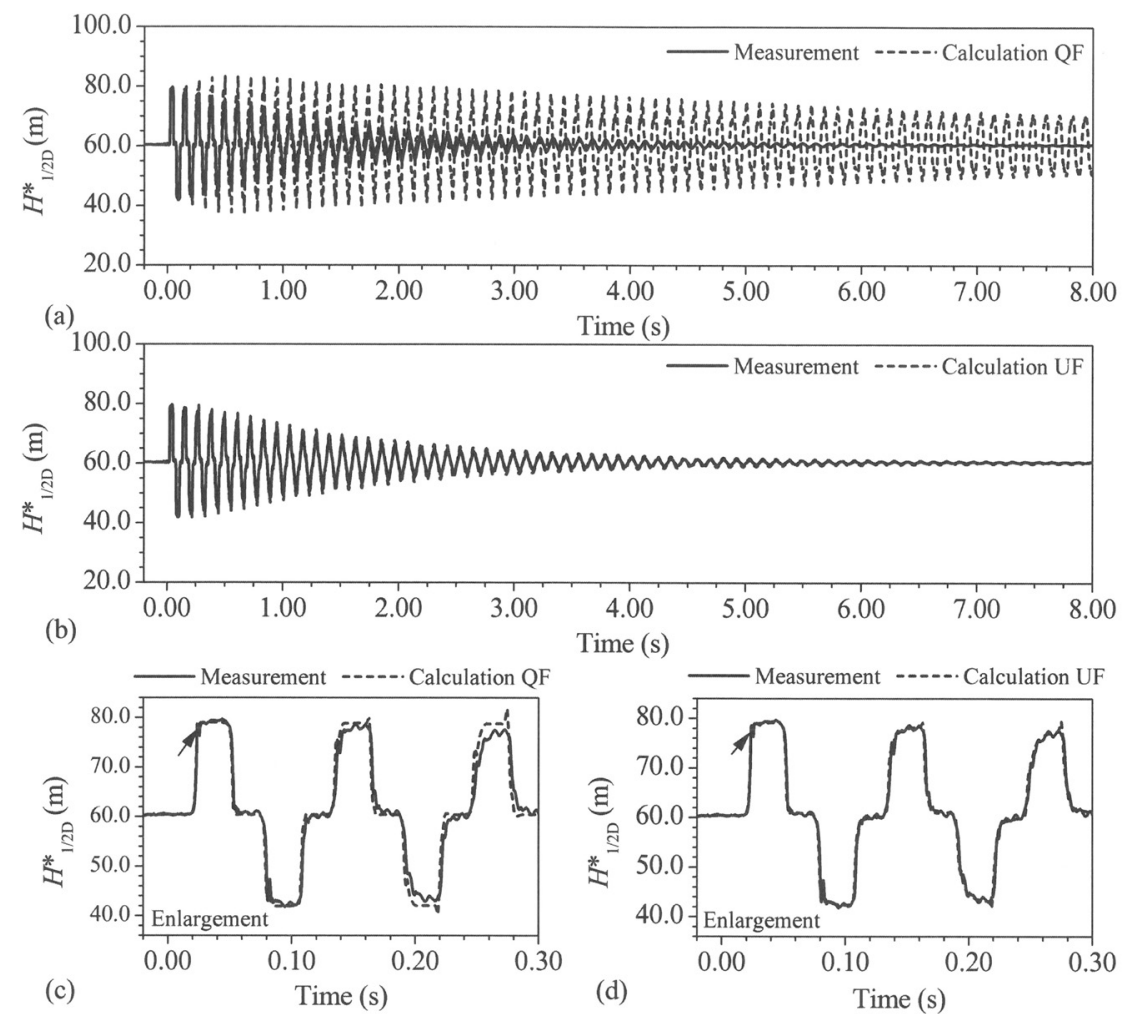

Fig. 6. Comparison of absolute heads at the midpoint $\left(H_{1 / 2 \mathrm{D}}^{*}\right)$ in Adelaide apparatus: $H_{T 1}=51 \mathrm{~m} ; \forall_{\mathrm{g} 0,1 / 2 \mathrm{U}}=0.39 \mathrm{~cm}^{3}$

(position $1 / 2 \mathrm{D}$ in Fig. 2). This occurs about $L /(2 a)$ in time after the valve closure as marked in Fig. 6 with the arrow in the $H^{*}{ }_{1 / 2 \mathrm{D}}$-absolute head history. At about $L / a$ after the valve closure the spiky pressure drop arrives at the closed valve (as marked with the arrow in the $H_{2 / 2}^{*}$-absolute head history in Fig. 5). The results from DGCM using the QF model differ significantly from the measured results (Figs. 5a and 5c for $H_{2 / 2}^{*}$; Figs. 6a and $6 \mathrm{c}$ for $H_{1 / 2 \mathrm{D}}^{*}$ ). The long-time simulations clearly show that the effects cumulate to such an extent that beat develops (Figs. 5a and 6a). The pressure envelope with increasing and decreasing pressure may be visualized. Finally, the pressure starts slowly to decay. When the time window is shortened (Fig. 5c and to a lesser extent Fig. 6c), the beginning of a damped beat on top of damped water-hammer may be observed in the experiment as well. It is evident that the quasi-steady friction model does not produce sufficient damping both for the bulk pressure traces as for the short-duration pressure peaks. Again, an attempt has been made to overcome this deficiency by using the UF model. The results from DGCM using UF are compared with the results of measurements in Figs. $5 \mathrm{~b}$ and $5 \mathrm{~d}$ for $H^{*}{ }_{2 / 2}$, and Figs. $6 \mathrm{~b}$ and $6 \mathrm{~d}$ for $H^{*}{ }_{1 / 2 \mathrm{D}}$. The long-time simulations show that the beat quickly damps out. When the time window is shortened weak experimental and numerical beats may be observed (Figs. 5d and 6d). The unsteady friction model does produce sufficient damping both for the bulk pressure traces and for the short-duration pressure peaks.

\section{CONCLUSIONS}

Theoretical and experimental investigations show that a single air pocket trapped in a water-filled pipeline creates distinct changes of amplitude, shape and timing of pressure waves. The severity of the resulting hydraulic transients depends on the size, pressure and position of the trapped air pocket. In the DGCM the trapped air pockets are incorporated as internal and end boundary conditions in the MOC scheme. Experiments with one trapped air pocket have been performed in two laboratory test facilities including tests with flow starting from rest (start-up case) and tests with flow stoppage (shut-down case). A trapped air pocket is confined either at the downstream deadend or captured in a special device near the midpoint of the pipeline, respectively. The dynamic response of the elastic liquid column due to a trapped air pocket in these apparatuses should be similar for both small and 
large pipelines with similar scalings. The results from DGCM using the QF model significantly differ from the measured results in both test cases. The quasi-steady friction model does not produce sufficient damping both for the bulk pressure traces as for the shortduration pressure peaks. An attempt has been made to overcome this deficiency by using a convolutionbased UF model. The unsteady friction model does produce sufficient damping both for the bulk pressure traces and the short-duration pressure peaks and it is recommended for long-duration hydraulic transient analysis. The short duration peaks due to interaction of pressure waves in water-filled pipelines with trapped air pockets have been investigated in depth for the first time.

\section{ACKNOWLEDGEMENTS}

The authors gratefully acknowledge the support of the Slovenian Research Agency (ARRS) conducted through the project L2-5491 Unsteady skin friction modelling in hydraulic piping systems.

\section{NOMENCLATURE}

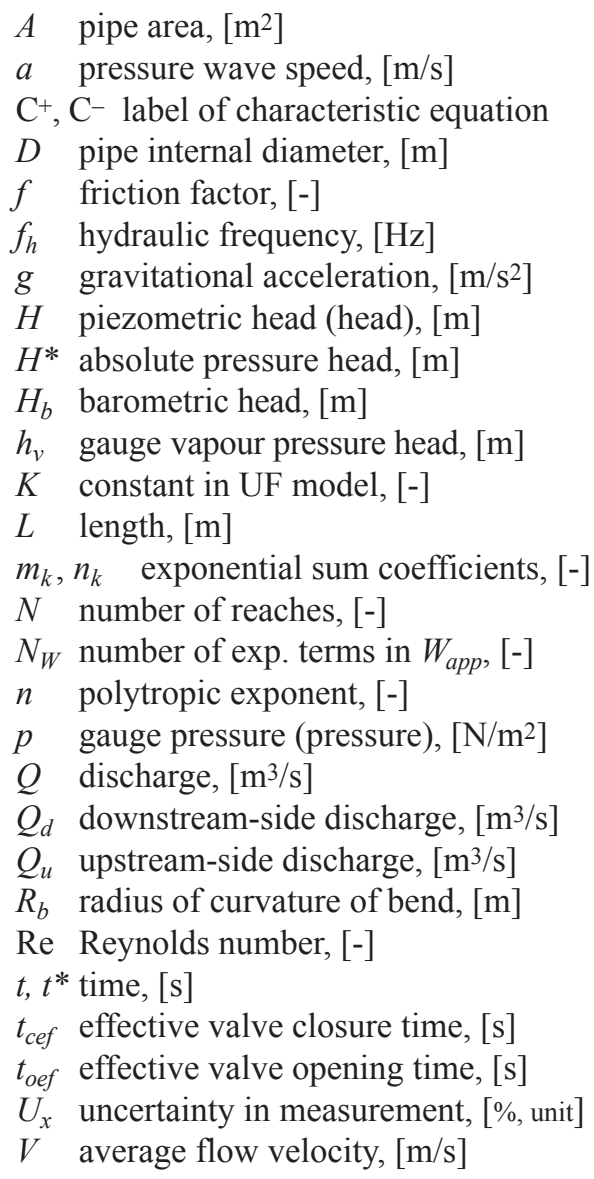

$W$ weighting function in UF model, [-]

$x$ distance, $[\mathrm{m}]$

$y_{k}$ component of the $W,\left[\mathrm{~m}^{3} / \mathrm{s}\right]$

$z$ elevation, $[\mathrm{m}]$

$\alpha_{g}$ gas void fraction, [-]

$\Delta t$ time step, [s]

$\Delta x$ space step or reach length, [m]

$\theta$ pipe angle, $[\mathrm{rad}]$

$v$ kinematic viscosity, $\left[\mathrm{m}^{2} / \mathrm{s}\right]$

$\tau$ dimensionless time, [-]

$\psi \quad$ weighting factor, [-]

$\forall_{g}$ gas cavity volume, $\left[\mathrm{m}^{3}\right]$

$\forall_{\text {reach }}$ pipe reach volume, $\left[\mathrm{m}^{3}\right]$

Subscripts:

app approximate

$g$ gas

$i$ node number

$s$ steady

T1 upstream-end pressurized tank

$u$ unsteady

0 initial condition

\section{REFERENCES}

[1] Lauchlan, C.S., Escarameia, M., May, R.W.P., Burrows, R., Gahan, C. (2005). Air in Pipelines. A Literature Review. Report SR 649, HR Wallingford Limited, Wallingford.

[2] Ramezani, L., Karney, B., Malekpour, A. (2016). Encouraging effective air management in water pipelines: a critical review. Journal of Water Resources, Planning and Management, vol. 142, no. 12, p. 04016053-1-11, D0l:10.1061/(ASCE) WR.1943-5452.0000695.

[3] Thorley, A.R.D. (2004). Fluid Transients in Pipeline Systems. A Guide to the Control and Suppression of Fluid Transients in Liquids in Closed Conduits. Professional Engineering Publishing Limited, London.

[4] Kruisbrink, A.C.H., Arregui, F., Carlos, M., Bergant, A. (2004). Dynamic performance characterisation of air valves. Proceedings of the 9th International Conference on Pressure Surges, p. 33-47.

[5] Wylie, E.B., Streeter, V.L. (1993). Fluid Transients in Systems. Prentice Hall, Englewood Cliffs.

[6] Bergant, A., Tijsseling, A.S., Vítkovský, J.P., Covas, D.I.C., Simpson, A.R., Lambert, M.F. (2008). Parameters affecting water-hammer wave attenuation, shape and timing-Part 2: Case studies. Journal of Hydraulic Research, vol. 46, no. 3, p. 382-391, D0l:10.3826/jhr.2008.2847.

[7] Campbell, A. (1983). The effect of air valves on surge in pipelines. Proceedings of the $4^{\text {th }}$ International Conference on Pressure Surges, p. 89-102.

[8] Ramezani, L., Karney, B., Malekpour, A. (2015). The challenge of air valves: A selective critical literature review. Journal of Water Resources, Planning and Management, vol. 141, no. 10, p. 04015017-1-11, D0I:10.1061/(ASCE)WR.19435452.0000530 . 
[9] Burrows, R., Qiu, D.Q. (1995). Effect of air pockets on pipeline surge pressure. Journal of Water Maritime and Energy. Proceedings of Institution of Civil Engineers, vol. 112, no. 4, p. 349-361, D0I:10.1680/iwtme.1995.28115.

[10] Martin, C.S. (1976). Entrapped air in pipelines. Proceedings of the $2^{\text {nd }}$ International Conference on Pressure Surges, p. F215-F2-28.

[11] Carlos, M., Arregui, F.J., Cabrera, E., Palau, C.V. (2011). Understanding air release through air valves. Journal of Hydraulic Engineering, vol. 137, no. 4, p. 461-469, DOI:10.1061/(ASCE)HY.1943-7900.0000324.

[12] Zhou, L., Liu, D., Wang, H., Ou, C., Long, A.X. (2015). Numerical comparison of rapid-filling-pipe models with trapped air. E-proceedings of the 36 th IAHR World Congress, Paper 80823.

[13] Duan, H.F., Ghidaoui, M.S., Lee, P.J., Tung, Y.K. (2012). Relevance of unsteady friction to pipe size and length in pipe fluid transients. Journal of Hydraulic Engineering, vol. 138, no. 2, p. 154-166, DOI:10.1061/(ASCE)HY.1943-7900.0000497.

[14] Bergant, A., Karadžić, U., Tijsseling, A.S. (2016). Dynamic water behaviour due to one trapped air pocket in a laboratory pipeline apparatus. IOP Conference Series. Earth and Environmental Science, vol. 49, p. 967-976, DOI:10.1088/1755-1315/49/5/052007.

[15] Bergant, A., Kim, Y., Tijsseling, A.S., Lambert, M.F., Simpson, A.R. (2009). Analysis of beat phenomena during transients with trapped air pocket. Proceedings of the 3 rd IAHR International Meeting of the Workgroup on Cavitation and Dynamic Problems in Hydraulic Machinery and Systems, Part II, p. 409-418.

[16] Vítkovský, J., Stephens, M., Bergant, A., Lambert, F., Simpson, A. (2004). Efficient and accurate calculation of Zielke and Vardy-Brown unsteady friction in pipe transients. Proceedings of the 9th International Conference on Pressure Surges, $p$. 405-419.

[17] Chaiko, M.A., Brinckman, K.W. (2002). Models for analysis of water hammer in piping with entrapped air. Journal of Fluids Engineering, vol. 124, no. 1, p. 194-204, DOl:10.1115/1.1430668.

[18] Malekpour, A., Karney, B.W. (2011). Rapid filling analysis of pipelines with undulating profiles by the method of characteristics. ISRN Applied Mathematics, vol. 2011, Article ID 930460, D0I:10.5402/2011/930460.

[19] Tijsseling, A.S., Hou, Q., Bozkuş, Z. (2015). Analytical expressions for liquid-column velocities in pipelines with entrapped gas. Proceedings of the ASME 2015 Pressure Vessels \& Piping Division Conference, Paper PVP2015-45184, DOI:10.1115/PVP2015-45184.

[20] Chaudhry, M.H. (2014). Applied Hydraulic Transients. $3^{\text {rd }}$ ed., Springer, New York, D0l:10.1007/978-1-4614-8538-4.

[21] Bergant, A., Simpson, A.R., Vítkovský, J. (2001). Developments in unsteady pipe flow friction modelling. Journal of Hydraulic Research, vol. 39, no. 3, p. 249-257, DOI:10.1080/00221680109499828.

[22] Pezzinga, G., Brunone, B. (2006). Turbulence, friction, and energy dissipation in transient pipe flow. Brocchini, M., Trivellato, F. (eds.), Vorticity and Turbulence Effects in Fluid Structure Interaction. WIT Press, Southampton, p. 213-236, DOl:10.2495/978-1-84564-052-1/09.
[23] He, S., Ariyaratne, C., Vardy, A.E. (2008). A computational study of wall friction and turbulence dynamics in accelerating pipe flows. Computers \& Fluids, vol. 37, no. 6, p. 674-698, D0l:10.1016/j.compfluid.2007.09.001.

[24] Vardy, A.E. (1980). Unsteady flows: fact and friction. Proceedings of the $3^{\text {rd }}$ International Conference on Pressure Surges, p. 15-26.

[25] Vardy, A.E., Brown, J.M.B., He, S., Ariyarante, C., Gorji, S. (2015). Applicability of frozen-viscosity models of unsteady wall shear stress. Journal of Hydraulic Engineering, vol. 141, no. 1, p. 04014064-1-13, DOI:10.1061/(ASCE)HY.19437900.0000930 .

[26] Meniconi, S., Duan, H.F., Brunone, B., Ghidaoui, M.S., Lee, P.J., Ferrante, M. (2014). Further developments in rapidly decelerating turbulent flow modelling. Journal of Hydraulic Engineering, vol. 143, no. 12, p. 04014028-1-9, Dol:10.1061/ (ASCE)HY.1943-7900.0000880.

[27] Martins, N.M.C., Brunone, B., Meniconi, S., Ramos, H.M., Covas, D.I.C. (2017). CFD and 1D approaches for the unsteady friction analysis of low Reynolds number turbulent flow. Journal of Hydraulic Engineering, vol. 147, no. 12, p. 04017050-1-13, DOI:10.1061/(ASCE)HY.1943-7900.0001372.

[28] Zielke, W. (1968). Frequency-dependent friction in transient pipe flow. Journal of Basic Engineering, vol. 90, no. 1, p. 109115, D0I:10.1115/1.3605049.

[29] Vardy, A.E., Brown, J.M.B. (2003). Transient turbulent friction in smooth pipe flows. Journal of Sound and Vibration, vol. 259, no. 5, p. 1011-1036, D0l:10.1006/jsvi.2002.5160.

[30] Vardy, A.E., Brown, J.M.B. (2004). Transient turbulent friction in fully rough pipe flows. Journal of Sound and Vibration, vol. 270, no. 1-2, p. 233-257, DOl:10.1016/S0022-460X(03)00492-9.

[31] Urbanowicz, K. (2015). Simple modelling of unsteady friction factor. Proceedings of the $12^{\text {th }}$ International Conference on Pressure Surges, p. 113-130.

[32] Urbanowicz, K. (2018). Fast and accurate modelling of frictional transient pipe flow. Zeitschrift für Angewandte Mathematik und Mechanik, vol. 98, no. 5, p. 802-823, DOI:10.1002/zamm.201600246.

[33] Schönfeld, J.C. (1949). Resistance and inertia of the flow of liquids in a tube or open canal. Applied Scientific Research, vol. 1, p. 169-197, Dol:10.1007/BF02120326.

[34] Chen, C.L. (1992). Momentum and energy coefficients based on power-law velocity profile. Journal of Hydraulic Engineering, vol. 118, no. 11, p. 1571-1584, D0l:10.1061/(ASCE)07339429(1992)118:11(1571).

[35] Coleman, H.W., Steele, W.G. (1989). Experimentation and Uncertainty Analysis for Engineers. John Wiley and Sons, New York.

[36] Kim, Y. (2008). Advanced Numerical and Experimental Transient Modelling of Water and Gas Pipeline Flows Incorporating Distributed and Local Effects. PhD thesis. University of Adelaide, Adelaide.

[37] VDI 3842:2004. Schwingungen in Rohrleitungssystemen. Vibrations in Piping Systems. Verein Deutscher Ingenieure, Düsseldorf.

[38] Simpson, A.R., Bergant, A. (1994). Numerical comparison of pipe-column-separation models. Journal of Hydraulic Engineering, vol. 120, no. 3, p. 361-377, Dol:10.1061/ (ASCE)0733-9429(1994)120:3(361). 